\title{
Characterization of the location and interfacial states of gallium in gallium/MCM-41 composites
}

\author{
Weiping Zhang a , Christopher I. Ratcliffe ${ }^{\text {a,* }}$, Igor L. Moudrakovski a ${ }^{\text {a }}$ John S. Tse ${ }^{\text {a }}$, \\ Chung-Yuan Mou ${ }^{\mathrm{b}}$, John A. Ripmeester ${ }^{\mathrm{a}}$ \\ ${ }^{a}$ Steacie Institute for Molecular Sciences, National Research Council of Canada, 100 Sussex Drive, Ottawa, Ont., Canada K1A 0R6 \\ ${ }^{\mathrm{b}}$ Department of Chemistry and Center of Condensed Matter Research, National Taiwan University, Taipei 106, Taiwan
}

Received 30 September 2004; received in revised form 5 November 2004; accepted 5 November 2004

Available online 6 January 2005

\begin{abstract}
A broad based approach, using nitrogen adsorption, X-ray diffraction, DSC, solid-state NMR and X-ray photoelectron spectroscopy, has been used to characterize a series of Ga/MCM-41 composite materials. Rather than filling the mesochannels of the MCM41 it is found, through this combination of techniques, that most of the Ga is present in the spaces between the particles of MCM-41. High-angle XRD and ${ }^{71} \mathrm{Ga}$ NMR indicate that at room temperature most of the Ga is in the liquid metal state. ${ }^{29} \mathrm{Si}$ and ${ }^{1} \mathrm{H}$ MAS NMR, and XPS reveal that at the Ga/MCM-41 interface the $\mathrm{Ga}$ reacts with silanol groups to form new $\mathrm{Ga}^{+}$states like $\mathrm{Si}-\mathrm{O}-\mathrm{Ga}$, or bridging $\mathrm{Si}(\mathrm{OH}) \mathrm{Ga}$ hydroxyls.
\end{abstract}

(C) 2004 Elsevier Inc. All rights reserved.

Keywords: Gallium-MCM-41 nano-composites; Porosimetry; PXRD; Solid-state NMR; XPS

\section{Introduction}

Nanostructured materials have attracted a great deal of attention because of their unique optical, electrical and mechanical properties which are different from those in the corresponding bulk substances [1,2]. Various metal and semiconductor nanocrystals have been synthesized in microporous and mesoporous materials [3,4], and carbon nanotubes [5]. Mesoporous silica MCM-41 has a regular array of discrete cylindrical channels with controllable mesopore size distribution $[6,7]$, which recent studies have suggested can provide a suitable framework to host semiconductor quantum dots and quantum wires $[4 \mathrm{e}, 8,9]$. This paper presents studies on Ga/MCM-41 composite materials. Since the melting point of bulk gallium metal is $29.9^{\circ} \mathrm{C}$ [10], li\footnotetext{
6775 .

* Corresponding author. Tel.: +1 613991 1240; fax: +1 613998

E-mail address: chris.ratcliffe@nrc-cnrc.gc.ca (C.I. Ratcliffe).
}

quid gallium might easily diffuse into the channels of MCM-41 under ambient conditions or slightly elevated temperatures to form nanowires, which would be expected to show quantum size effects. The general characterization of the materials posed quite a few challenges and surprises, and numerous different techniques, including porosimetry, low and high angle PXRD, DSC, and solid state NMR, were applied in order to reach a satisfactory conclusion on the whereabouts of the introduced Ga. Some of the experiments produced results which could have more than one interpretation, especially if taken in isolation. Also a number of methods sensitive to local chemistry and structure were used to try to shed new light on interactions between the MCM-41 framework and the gallium. These included ${ }^{29} \mathrm{Si}$ MAS NMR to determine the coordination around the silicon atoms [11], ${ }^{1} \mathrm{H}$ MAS NMR to quantitate the hydroxyl groups in the silica using an intensity reference material [12-14], and ${ }^{71}$ Ga NMR and X-ray photoelectron spectroscopy to reveal the $\mathrm{Ga}$ oxidation states. 


\section{Experimental section}

\subsection{Materials}

MCM-41 was prepared as described previously $[15,16]$ using cetyl-trimethyl-ammonium bromide $(\mathrm{CTAB})$ as the structure-directing agent. $8.6 \mathrm{~g}$ of fumed silica (Aldrich) was mixed with $13.8 \mathrm{~g}$ of water and $14.7 \mathrm{~g}$ of $25 \%$ tetramethyl-ammonium hydroxide aqueous solution (Aldrich). Then, a solution comprising $8.5 \mathrm{~g}$ of CTAB (Aldrich), $15.7 \mathrm{~g}$ of water and $2.8 \mathrm{~g}$ of ammonium hydroxide (Fisher Scientific) was added under vigorous stirring. The mixture was hydrothermally crystallized at $70^{\circ} \mathrm{C}$ for 3 days, then filtered and washed with deionized water. After drying in air at $120^{\circ} \mathrm{C}$ for $4 \mathrm{~h}$, the product was calcined at $550^{\circ} \mathrm{C}$ for $8 \mathrm{~h}$ to remove the template and obtain MCM-41 in the proton form.

MCM-41 samples were degassed under vacuum, and then measured amounts of gallium (purity 99.99\%, Strem Chemicals) were introduced under a high-purity nitrogen atmosphere. The mixture was stirred at $40^{\circ} \mathrm{C}$ for $\sim 2 \mathrm{~h}$ until a homogeneous sample was obtained. Finally, the sample was heated to $300{ }^{\circ} \mathrm{C}$ at $2{ }^{\circ} \mathrm{C} / \mathrm{min}$ under vacuum $\left(<10^{-2} \mathrm{~Pa}\right)$ and held in these conditions for $8 \mathrm{~h}$. The resultant Ga/MCM-41 composites were grey to black depending on the gallium loadings.

\subsection{Characterization}

Nitrogen adsorption-desorption isotherms were measured at $-196{ }^{\circ} \mathrm{C}$ using a Micromeritics ASAP 2010 porosimeter. The volume of adsorbed $\mathrm{N}_{2}$ was normalized to standard temperature and pressure. Samples were outgassed at $200{ }^{\circ} \mathrm{C}$ overnight before measurement, to remove water.

DSC measurements were carried out on a TA Instruments DSC 2920 with a heating rate of $5^{\circ} \mathrm{C} / \mathrm{min}$ from -90 to $+150{ }^{\circ} \mathrm{C}$. TGA was performed from room temperature to $250{ }^{\circ} \mathrm{C}$ using a TA Instruments 2050 Thermogravimetric Analyzer, with a heating rate of $5 \% \mathrm{~min}$.

Low-angle X-ray powder diffraction patterns were obtained at room temperature on a Scintag X2 Diffractometer using $\mathrm{CuK}_{\alpha}$ radiation $(\lambda=1.5406 \AA)$. Diffraction data were collected between $2 \theta$ of $1^{\circ}$ and $8^{\circ}$ with a scanning speed of $0.5^{\circ} / \mathrm{min}$. High-angle XRD patterns were recorded between $2 \theta$ of $25^{\circ}$ and $60^{\circ}$ at various temperatures on a Rigaku X-ray Diffractometer using $\mathrm{CoK}_{\alpha}$ radiation $(\lambda=1.7902 \AA)$.

${ }^{29} \mathrm{Si}$ MAS NMR spectra were obtained at $59.6 \mathrm{MHz}$ (Bruker AMX-300 spectrometer) using a $7 \mathrm{~mm}$ probe (Doty Scientific Inc.) with a spinning rate of $5 \mathrm{kHz}$, a $180 \mathrm{~s}$ recycle delay and 1600 scans. ${ }^{29} \mathrm{Si}$ chemical shifts were referenced to tetramethylsilane (TMS). ${ }^{1} \mathrm{H}$ MAS NMR spectra were obtained at $400.1 \mathrm{MHz}$ (Bruker DSX-400) using a Bruker $4 \mathrm{~mm}$ MAS probe, with a sample spinning rate of $8 \mathrm{kHz}$, a $12 \mathrm{~s}$ recycle delay and
96 scans. ${ }^{1} \mathrm{H}$ chemical shifts were referenced to adamantane, at $1.74 \mathrm{ppm}$ relative to TMS. The samples for ${ }^{1} \mathrm{H}$ NMR were dehydrated at $200{ }^{\circ} \mathrm{C}$ and pressures below $10^{-2} \mathrm{~Pa}$ for $10 \mathrm{~h}$ before being loaded into zirconia rotors in a dry box. In an attempt to quantitate the amounts of different $\mathrm{H}$ species present, each sample was weighed and its ${ }^{1} \mathrm{H}$ NMR spectrum calibrated against that of a known amount of 1,1,1,3,3,3-hexafluoro-2-propanol (Aldrich) [13,14]. The sample with $65.1 \mathrm{wt} \%$ Ga would not spin in the magnetic field. Static room temperature

${ }^{71} \mathrm{Ga}$ NMR spectra were acquired at $182.9 \mathrm{MHz}$ (Varian Inova-600) using a home-built probehead with a $5 \mathrm{~mm}$ coil with a recycle delay of $0.1 \mathrm{~s}$ and 1024 to $\sim 80,000$ scans depending on the gallium loadings. A $1 \mathrm{M}$ aqueous solution of $\mathrm{Ga}_{2}\left(\mathrm{SO}_{4}\right)_{3}$ was used as the chemical shift reference. Also, quantitative ${ }^{71}$ Ga NMR measurements of the Ga liquid line were obtained at $91.49 \mathrm{MHz}$ (Bruker AMX 300). Weighed amounts of sample were measured under the same NMR acquisition conditions relative to a known quantity of $11.04 \mathrm{wt} \% \mathrm{Ga}\left(\mathrm{NO}_{3}\right)_{3}$ aqueous solution.

X-ray photoelectron spectra were recorded on a Kratos Ultra XPS instrument using monochromatic $\mathrm{AlK}_{\alpha}$ radiation. A survey spectrum was run between 1400 and $0 \mathrm{eV}$ to determine the elements present on the surface. High-resolution spectra were then recorded on the elements of interest for peak shape and position.

\section{Results and discussion}

There are many difficulties associated with the characterization of nanostructured materials, and the problems are compounded when it comes to locating materials which have been introduced into a porous framework. Probably the most direct means of demonstrating the presence of $\mathrm{Ga}$ in the channels of MCM41 would be transmission electron microscopy, however, attempts to obtain TEM pictures were unsuccessful due to movement of the sample under the conditions in the spectrometer. In fact metal/SBA-15 (MCM-41) composites do not show clear TEM images with high metal loadings [4d]. Consequently one must rely on a synoptic approach, piecing together complementary information from numerous and diverse techniques in a fully selfconsistent fashion, in order to produce a coherent picture of these materials.

\subsection{Porosimetry}

Important information for the discussion of the location of the gallium in MCM-41 is provided by the lowtemperature $\mathrm{N}_{2}$ physisorption isotherms shown in Fig. 1. Empty MCM-41 shows a typical stepped Type IV isotherm with two regions of strong $\mathrm{N}_{2}$ uptake [17]. It is unusual that there is hysteresis in both regions. The hys- 


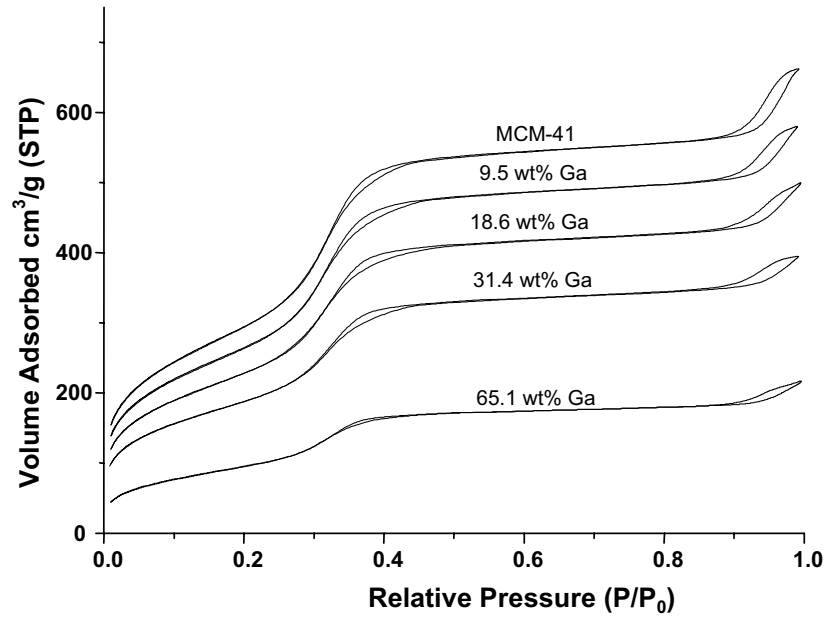

Fig. 1. $\mathrm{N}_{2}$ physisorption isotherms of $\mathrm{Ga} / \mathrm{MCM}-41$ composites with different metallic gallium loadings measured at $-196{ }^{\circ} \mathrm{C}$, plotted as volume adsorbed per gram of sample so that the curves are well separated.

teresis loop at the low relative pressure of 0.4 corresponds to the capillary condensation of $\mathrm{N}_{2}$ within the primary mesochannels of MCM-41, while that at high relative pressure (above 0.8 ) is attributed to the capillary condensation of $\mathrm{N}_{2}$ into larger secondary pores (presumably these are inter-particle voids) [18a,b].

Table 1 presents the standard parameters derived from the $\mathrm{N}_{2}$ isotherms using the instrumental software, i.e. specific surface areas determined from the linear part of the BET equation $\left(p / p_{0}=0.06-0.20\right)$, pore volumes and pore sizes calculated using the desorption branch of the isotherms and the Barrett-Joyner-Halenda (BJH) formula [19]. The numbers for the empty MCM-41 indicate that our sample is a typical mesoporous material [7].

The main conclusions which may be drawn from the results in Table 1 are that as more Ga is introduced (i) the average channel pore size does not appear to change, and (ii) only a small fraction of the channel space becomes inaccessible even at the highest loading of $65.1 \mathrm{wt} \%$. The first suggests that the channel space which is still accessible to $\mathrm{N}_{2}$ does not have Ga coating its walls, since this would reduce the measured channel diameter, and consequently one might infer that the Ga forms plugs rather than wetting the silica surface. The second conclusion is crucial and indicates that most of the channel space is not occupied by Ga. However, the exact location of all the Ga remains unclear. Furthermore, those channels which are no longer accessible to $\mathrm{N}_{2}$ are not necessarily filled with $\mathrm{Ga}$. They could simply be blocked with a tiny amount of $\mathrm{Ga}$ at both ends, or they could be partially or totally filled. The maximum amount of $\mathrm{Ga}$ which could totally fill the inaccessible space can be calculated based on the pore volume. However, we prefer to use a better estimate of the pore volume based on the powder X-ray data, see below.

\subsection{Low-angle PXRD}

The low-angle PXRD patterns of calcined MCM-41 with different metallic gallium loadings, Fig. 2, all display three reflection peaks that can be indexed to the (100), (110) and (200) diffraction lines characteristic of the hexagonal structure. From the d-spacings one can calculate the lattice constant $a=44.0 \AA$, which is also the distance between the centers of adjacent channels. The data indicate that the parent calcined MCM-41 silica is of high quality, and that the ordered hexagonal mesostructure remains intact after adding gallium. The intensity of the three reflections gradually

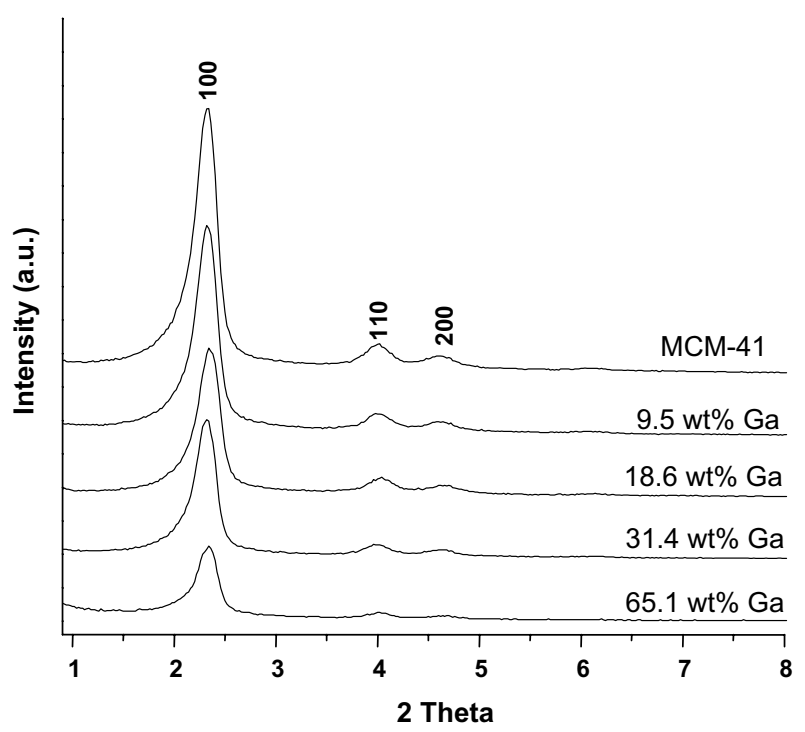

Fig. 2. Low-angle XRD patterns of calcined mesoporous MCM-41 with different metallic gallium loadings (room temperature, $\mathrm{CuK}_{\alpha}$ radiation).

Table 1

Surface areas, channel volumes and sizes of MCM-41 before and after introducing metallic gallium

\begin{tabular}{llll}
\hline Samples & BET surface area $\left(\mathrm{m}^{2} / \mathrm{g}\right.$ MCM-41) & Channel volume $\left(\mathrm{cm}^{3} / \mathrm{g}\right.$ MCM-41) & BJH desorption channel size $(\AA)$ \\
\hline MCM-41 & 1104 & 0.98 & 31.3 \\
$9.5 \mathrm{Ga} /$ MCM-41 & 1098 & 0.94 & 30.6 \\
$18.6 \mathrm{Ga} /$ MCM-41 & 1058 & 0.91 & 31.0 \\
$31.4 \mathrm{Ga} /$ MCM-41 & 1039 & 0.82 & 29.2 \\
$65.1 \mathrm{Ga} /$ MCM-41 & 859 & 0.71 & 32.1 \\
\hline
\end{tabular}


decreases with increasing gallium loading, but the interpretation of this observation with regard to locating the gallium is ambiguous: Channel filling changes the $\mathrm{X}$-ray scattering contrast between the channels and the walls of the mesoporous material [20,21], and if gallium were gradually filling the channels, one would expect the intensity of the peaks first to decline, as observed, but then intensity should grow again, since the scattering from gallium would dominate at high loadings. If such behaviour had been observed it would have been definitive evidence for $\mathrm{Ga}$ filling the channels. Thus one might conclude that there is only partial filling of the channels. Note that any gallium between MCM-41 particles rather than inside the channels would not contribute to the intensity of the three peaks. However, a secondary factor to consider is Xray absorption by the gallium, which should cause a continuous decline in the intensity of the scattered Xrays as gallium is loaded. Moreover, gallium both inside and/or outside the channels will cause X-ray absorption.

A more reasonable channel diameter can now be calculated for the empty MCM-41, using the Kruk-Jaroniec-Sayari (KJS) geometrical model [22], for which the following relationship has been derived:

$w=c d\left[\rho V_{\mathrm{p}} /\left(1+\rho V_{\mathrm{p}}\right)\right]^{1 / 2}$,

where $w=$ channel diameter, $c=[8 /(\pi \sqrt{ } 3)]^{1 / 2}, d=$ the $d_{100}$ lattice spacing, $\rho=$ density of wall (taken as the density of amorphous silica, $2.2 \mathrm{~g} / \mathrm{cc}$ ) and $V_{\mathrm{p}}=$ pore volume. With $d=38.1 \AA$ and $V_{\mathrm{p}}=0.98 \mathrm{cc} / \mathrm{g}$ of MCM- 41 one obtains $w=38.2 \AA$, which is typical for an MCM41 prepared with a $\mathrm{C}_{16}$ chain surfactant using this model [23]. The $\mathrm{BJH}$ method tends to underestimate $w$ significantly, whereas the KJS model may overestimate slightly.

Conversely one may use the KJS model to calculate expected $V_{\mathrm{p}}$ values for different values of $w$, based on the X-ray $d_{100}$ spacing. Then taking the density of gallium to be $6.01 \mathrm{~g} / \mathrm{cc}$ (the average of the densities of solid $\alpha$-phase and liquid Ga), the amount of gallium required to fill the inaccessible pore space in the composites can be calculated, see Table 2. This will be an estimate of the maximum amount of intra-channel gallium, but, as mentioned above, the real amount could be anywhere from almost zero to this maximum level. The results are very sensitive to the channel size, and in the case of the smaller $(\mathrm{BJH})$ channel size the numbers show that it would be impossible to have all the Ga inside. For some of the loadings at the more probable $38 \AA$ (KJS) size, however, all the Ga could fit inside. Thus at this point the location of all the gallium is still uncertain.

\subsection{High-angle PXRD}

Fig. 3 shows the high-angle PXRD patterns of the asprepared $\mathrm{Ga} / \mathrm{MCM}-41$ composites at room temperature.

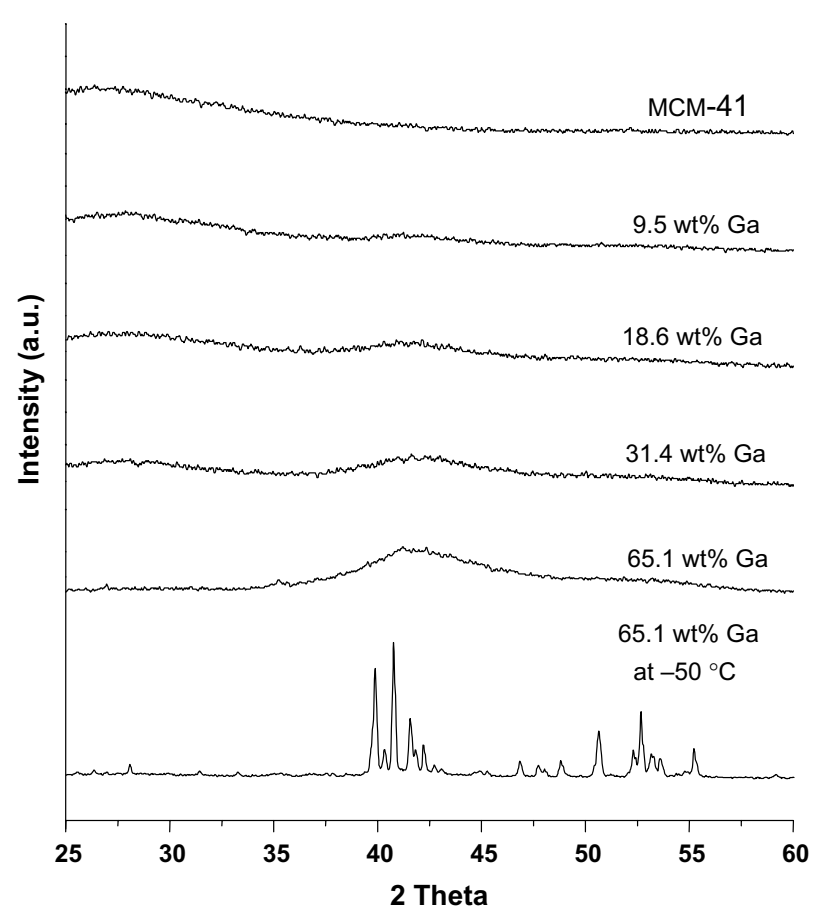

Fig. 3. High-angle XRD patterns of calcined mesoporous MCM-41 with different $\mathrm{Ga}$ loadings at room temperature, and, at the bottom, of $65.1 \mathrm{wt} \% \mathrm{Ga} / \mathrm{MCM}-41$ at $-50{ }^{\circ} \mathrm{C}\left(\mathrm{CoK}_{\alpha}\right.$ radiation $)$.

Table 2

The maximum gallium content for channels of different sizes

\begin{tabular}{llllll}
\hline & $\begin{array}{l}\text { Total Ga available } \\
(\mathrm{g} / \mathrm{g} \text { MCM-41) }\end{array}$ & $\begin{array}{l}\text { Inaccessible } \\
\text { pore space }(\%)^{\mathrm{a}}\end{array}$ & \multicolumn{3}{l}{$\begin{array}{l}\text { Calculated maximum intra-channel Ga content }(\mathrm{g} / \mathrm{g} \text { MCM-41) for } \\
\text { different channel sizes }\end{array}$} \\
\cline { 3 - 6 } & & 1.0 & $0.025 \AA\left(V_{\mathrm{p}}=0.420^{\mathrm{b}}\right)$ & $35 \AA\left(V_{\mathrm{p}}=0.613\right)$ & $38 \AA\left(V_{\mathrm{p}}=0.953\right)$ \\
\hline $9.5 \% \mathrm{Ga}$ & 0.105 & 4.5 & 0.113 & 0.037 & 0.166 \\
$18.6 \% \mathrm{Ga}$ & 0.229 & 9.1 & 0.230 & 0.335 & 0.258 \\
$31.4 \% \mathrm{Ga}$ & 0.458 & 25.4 & 0.641 & 0.936 & 0.521 \\
$65.1 \% \mathrm{Ga}$ & 1.865 & & & 3.455 \\
\hline
\end{tabular}

${ }^{a}$ The isotherms were found to scale in the region where $\mathrm{N}_{2}$ is absorbed into the channels $\left(p / p_{0}=0.2-0.5\right)$, so it was possible to calculate the pore volumes relative to empty MCM-41 from the raw data. This circumvents any effects of model dependence inherent in pore volumes calculated using the instrument software.

${ }^{\mathrm{b}} V_{\mathrm{p}}$ values (cc/g MCM-41) calculated using the KJS formula. 
A broad reflection peak is observed at around $28^{\circ}$ arising from the diffraction of the amorphous framework of MCM-41 [24]. With increasing gallium loading, a broad signal appears gradually between $37^{\circ}$ and $47^{\circ}$ (centred about $42^{\circ}$ ) in the patterns. This can be ascribed to liquid gallium, whose freezing temperature in confined spaces is decreased significantly below the melting point of bulk $\alpha$-gallium $[25,26]$.

The PXRD results for lower temperatures (one example is given at the bottom of Fig. 3 for $-50^{\circ} \mathrm{C}$ ) show numerous relatively sharp diffraction lines which can be indexed on various solid phases of $\mathrm{Ga}(\alpha, \beta, \gamma$ and possibly $\delta$ ). The lines for each of these phases disappear above their respective melting temperatures, and are replaced by the broad liquid line, which increases in intensity after each melting. Unusual phase behaviour in finely divided $\mathrm{Ga}$ has been observed before [25b,26] and the results will be discussed in this context in detail in a later paper.

From the perspective of the current discussion, however, a more important observation is that the PXRD lines of the solid phases are much narrower than would be expected for material confined to a 31-38 A channel. This is crucial to our understanding and characterization of these materials. The Scherrer equation [27],

$D=K \lambda / \beta \cos \theta$

(where $D=$ particle diameter, $\lambda=\mathrm{X}$-ray wavelength, $\beta=$ linewidth in $2 \theta$ in radians, $\theta=$ angle at which the line is observed, and $K=$ the shape factor which is usually given the value 0.9 for spherical particles), allows an estimate to be made of the expected linewidth. For $3.8 \mathrm{~nm}$ particles a linewidth of $2.59^{\circ}$ is expected at $2 \theta=40^{\circ}$ ( $3.17^{\circ}$ for $\left.3.1 \mathrm{~nm}\right)$. This is 14 times broader than the observed linewidth of $0.19^{\circ}$ on a peak at $2 \theta=40.4^{\circ}$. This observed linewidth corresponds to a minimum (since no instrumental broadening correction was made) gallium particle size of $52 \mathrm{~nm}$. The conclusion has to be that the solid phases of Ga giving rise to the sharp PXRD patterns cannot be inside the channels of the MCM-41, but instead exist in the larger inter-particle spaces. Furthermore, at temperatures where all these crystal phases are present, it was not possible to detect any other PXRD intensity which might be ascribed to gallium within the channels, either as amorphous scattering or as broadened crystalline peaks. These PXRD results are probably the most convincing evidence we have for placing most of the $\mathrm{Ga}$ outside the channels.

\subsection{DSC/TGA}

The multiphase behaviour of gallium below room temperature was confirmed by DSC, and these results will be discussed in the later paper. However, besides the sharp thermal peaks which can be assigned to melting of various crystalline gallium phases, the DSC scans

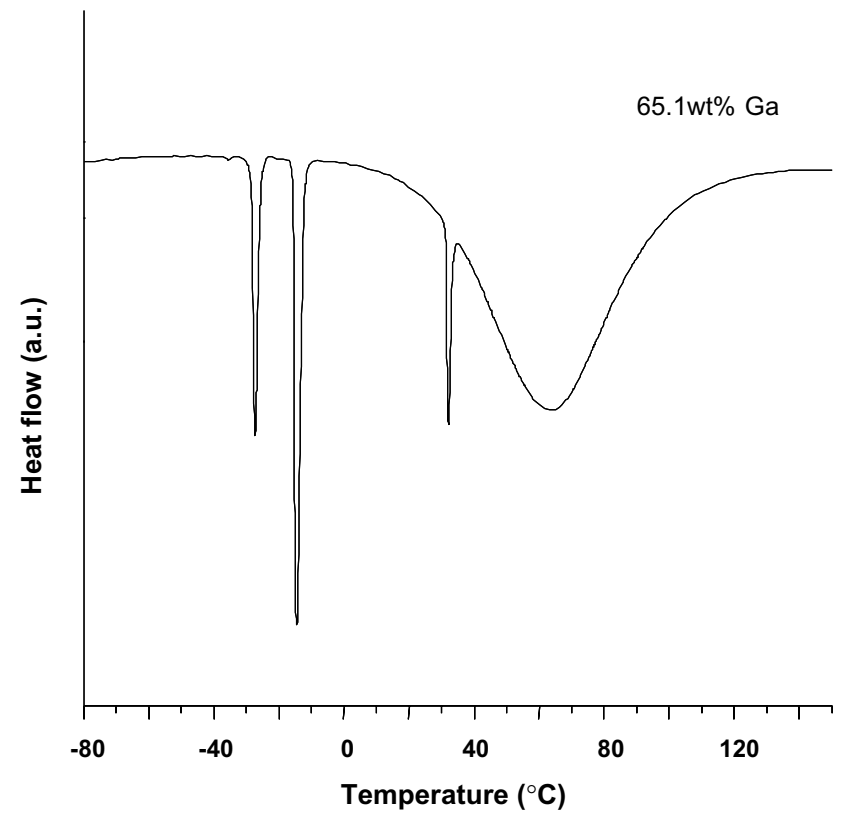

Fig. 4. DSC scan of $65.1 \mathrm{wt} \% \mathrm{Ga} / \mathrm{MCM}-41$. In order of ascending temperature, the three sharp peaks correspond to the melting of three different solid phases of gallium: (i) unidentified (ii) $\beta$-phase (iii) $\alpha$ phase. The very broad peak centred about $50{ }^{\circ} \mathrm{C}$ is due to loss of absorbed water.

showed a strong, broad peak above room temperature peaking at $\sim 50{ }^{\circ} \mathrm{C}$, Fig. 4 . This initially caused some confusion, especially since this peak disappeared if the same sample was then cooled and scanned again. TGA however, showed a mass loss in the same temperature range. The composite samples were able to absorb water when exposed to air, like empty MCM-41, which was expelled again on the first heating cycle. This provides further evidence that the pores are not completely filled by gallium. Furthermore, no other thermal events were observed in the DSC, which might have been ascribed to the presence of $\mathrm{Ga}$ inside the channels.

\section{5. ${ }^{1} H$ MAS NMR}

${ }^{1} \mathrm{H}$ MAS NMR, in principle, is a very useful tool to study the hydroxyl groups since it can measure the hydrogen atoms in MCM-41 directly. Compared with IR, ${ }^{1} \mathrm{H}$ MAS NMR can provide quantitative information on the hydroxyl groups, after appropriate calibration, without the difficulties associated with extinction coefficients [13,14]. As shown in Fig. 5, empty MCM41 exhibits a resonance at $1.7 \mathrm{ppm}$ with a broad shoulder to low field at $2.4 \mathrm{ppm}$, assigned to the single $(\mathrm{Si}-\mathrm{O}-\mathrm{H})$ and hydrogen-bonded $(\mathrm{Si}-\mathrm{HO} \cdots \mathrm{H}-\mathrm{O}-\mathrm{Si})$ surface silanol groups, respectively [28,29]. Physisorbed water is absent after evacuation at $200{ }^{\circ} \mathrm{C}$. Quantitative analysis of the empty MCM-41 spectrum shows that the total number of silanol groups is $3.77 \mathrm{mmol} / \mathrm{g}$ (see Table $3)$, consistent with that reported previously $[28,29]$. As 


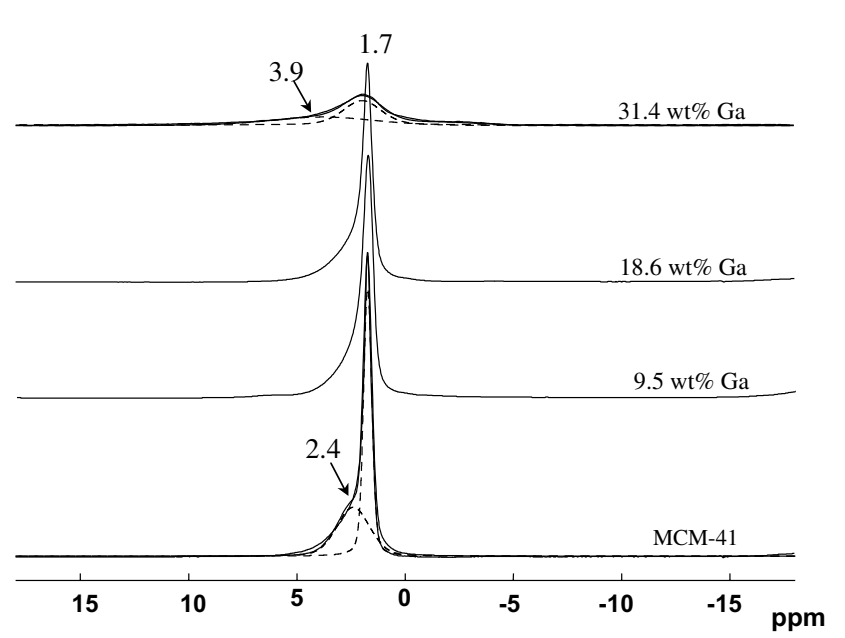

Fig. 5. ${ }^{1} \mathrm{H}$ MAS NMR spectra at $400 \mathrm{MHz}$ of MCM-41 with different Ga loadings.

gallium is introduced the intensities of the single and hydrogen-bonded silanol lines decrease. The reduction is very significant when the $\mathrm{Ga}$ loading reaches $31.4 \mathrm{wt} \%$, and while the position of the single silanol is unchanged its linewidth increases and a new, broad signal appears, centered at $\sim 3.9 \mathrm{ppm}$. (The line broadening may be an effect of metallic Ga on nearby ${ }^{1} \mathrm{H}$ nuclei at the higher Ga loading.) This new line can be assigned to the $\mathrm{Si}(\mathrm{OH})-\mathrm{Ga}$ bridging hydroxyls, since its chemical shift is in the range 3.8-4.0 ppm observed for bridging hydroxyls in aluminosilicate zeolites [12], and very close to the $4.0 \mathrm{ppm}$ observed for $\mathrm{Si}(\mathrm{OH})-\mathrm{Ga}$ of gallosilicates $[30,31]$.

The quantitative results, Table 3 , show that between empty MCM-41 and the $31.4 \mathrm{wt} \%$ Ga loading the number of single silanols detected decreases from 2.22 to $0.14 \mathrm{mmol} / \mathrm{g}$, hydrogen-bonded silanols disappear, and overall there is a loss of most of the $\mathrm{OH}$ to the extent of $3.77-0.25=3.52 \mathrm{mmol}$. There are good reasons for suspecting that in fact not all the ${ }^{1} \mathrm{H}$ are detected, so that while the results do give quantitatively the amount of detectable ${ }^{1} \mathrm{H}$ they are probably not a reliable reflection of the actual number of ${ }^{1} \mathrm{H}$ present in the samples. Nevertheless, the ${ }^{1} \mathrm{H}$ NMR does indicate that there is some reaction of the metallic $\mathrm{Ga}$ in contact with the surfaces of the MCM-41 with the weakly acidic single and hydrogen-bonded silanols, to produce $\mathrm{Si}-\mathrm{O}-\mathrm{Ga}$ species.

\section{6. ${ }^{29} \mathrm{Si} M A S N M R$}

${ }^{29}$ Si MAS NMR spectra for different Ga loadings are shown in Fig. 6. Empty MCM-41 shows three peaks at $-110,-101$ and $-92 \mathrm{ppm}$, which can be assigned to $Q^{4}$ $\left(\mathrm{Si}(\mathrm{OSi})_{4}\right), Q^{3}\left(\mathrm{Si}(\mathrm{OSi})_{3}(\mathrm{OH})\right)$ and $Q^{2}\left(\mathrm{Si}(\mathrm{OSi})_{2}(\mathrm{OH})_{2}\right)$ species, respectively $[28,29,32]$. The $Q^{3}$ species are associated with single $\mathrm{SiOH}$ groups; which can also be hydrogen-bonded, and the $Q^{2}$ species correspond to the geminal silanols. Deconvolution of the spectrum for empty MCM-41 into three Gaussian lines and subsequent integration yields the ratio of $Q^{4}: Q^{3}: Q^{2}=$ 59.3:30.6:10.1, i.e. about $40 \%$ of the silicon atoms have attached $\mathrm{OH}$. As increasing amounts of $\mathrm{Ga}$ are introduced, the changes, if any, in the spectra are very minor. If any $\mathrm{Ga}$ reacts to give SiOGa then unfortunately the shifts for this type of $\mathrm{Si}$ will be in the same region as the $\mathrm{SiOH}$ [33]: In the gallosilicate analcime the resonance for $\mathrm{SiOGa}$ is at $-100.17 \mathrm{ppm}$ and $\mathrm{Si}(\mathrm{OGa}) 2$ at $-93.29 \mathrm{ppm}$ [33]. This also makes it unreasonable to attempt deconvolution for the Ga/MCM-41 composites. Thus the ${ }^{29} \mathrm{Si}$ spectra will not be very sensitive to changes in the relative amounts of $\mathrm{SiOH}$ and SiOGa as the Ga loading increases.

From the formula weight of $\mathrm{SiO}_{2}=60.09 \mathrm{~g} / \mathrm{mol}$ we can estimate that there is $\sim 16.7 \mathrm{mmol}$ of $\mathrm{SiO}_{2}$ per gram

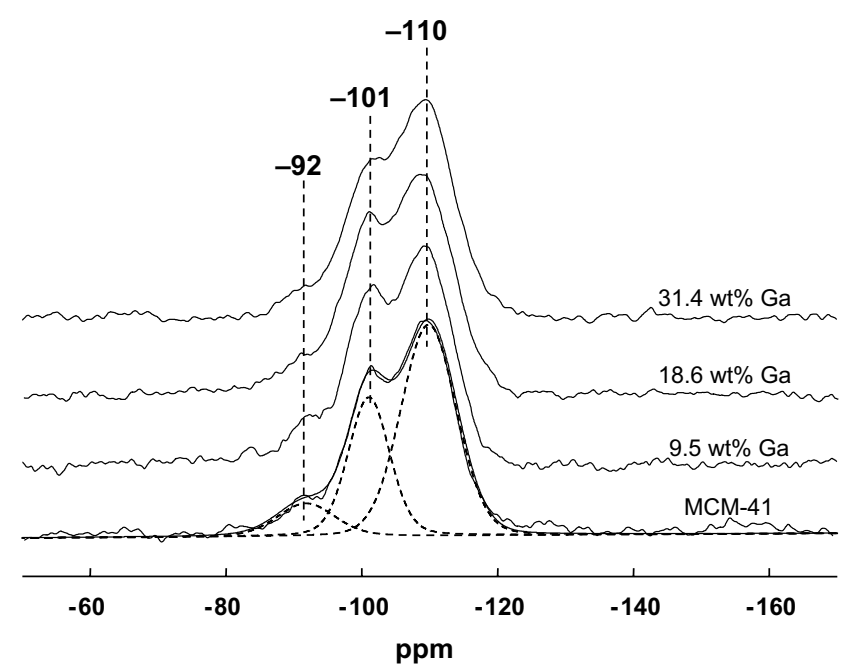

Fig. $6 .{ }^{29} \mathrm{Si}$ MAS NMR spectra at $59.6 \mathrm{MHz}$ of MCM-41 with different Ga loadings.

Table 3

Amounts of hydroxyls in Ga/MCM-41 (mmol/g of MCM-41) observed using ${ }^{1} \mathrm{H}$ NMR

\begin{tabular}{lllll}
\hline $\begin{array}{l}\text { Ga loading } \\
(\mathrm{wt} \%)\end{array}$ & $\begin{array}{l}\text { Amount of } \\
\text { single silanols }\end{array}$ & $\begin{array}{l}\text { Amount of hydrogen-bonded } \\
\text { silanols }\end{array}$ & $\begin{array}{l}\text { Amount of } \\
\text { bridging hydroxyls }\end{array}$ & $\begin{array}{l}\text { Total amount } \\
\text { of hydroxyls }\end{array}$ \\
\hline 0 & 2.22 & 1.55 & 0 & 3.77 \\
9.5 & 1.44 & 1.17 & 0 & 2.61 \\
18.6 & 1.18 & 1.09 & 0 & 2.27 \\
31.4 & 0.14 & 0 & 0.11 & 0.25 \\
\hline
\end{tabular}


of empty MCM-41, which according to its $Q^{4}: Q^{3}: Q^{2}$ ratio divides into $9.9 \mathrm{mmol} / \mathrm{g}$ of $Q^{4}, 5.1 \mathrm{mmol} / \mathrm{g}$ of $Q^{3}$ and $1.7 \mathrm{mmol} / \mathrm{g}$ of $Q^{2}$. Hence there should be $5.1+2 \times 1.7=8.5 \mathrm{mmol} / \mathrm{g}$ of $\mathrm{OH}$ groups in empty MCM-41, which is considerably more than the $3.77 \mathrm{mmol} / \mathrm{g}$ measured by the quantitative ${ }^{1} \mathrm{H} \mathrm{NMR}$. However, in silica gels not all the ${ }^{1} \mathrm{H}$ signals are narrowed by MAS because of dynamics effects [34], and perhaps similar effects can account for at least some of the missing ${ }^{1} \mathrm{H}$ intensity in $\mathrm{MCM}-41$ and the $\mathrm{Ga} /$ MCM-41 composites. Certainly, it is clear that although the quantitative ${ }^{1} \mathrm{H}$ measurements do monitor disappearing $\mathrm{OH}$ intensity they cannot give a reliable estimate of how much has disappeared due to reaction with gallium and how much is just invisible. The presence of metallic gallium may also be reducing the amount of sample which is observed in the NMR experiment.

\section{7. ${ }^{71} \mathrm{Ga} N M R$}

Of the two NMR-active isotopes ${ }^{69} \mathrm{Ga}(60.4 \%$ abundance) and ${ }^{71} \mathrm{Ga}(39.6 \%),{ }^{71} \mathrm{Ga}$ is more attractive for study because of its smaller quadrupole moment, larger magnetogyric ratio and slightly higher absolute sensitivity [35]. The static ${ }^{71} \mathrm{Ga}$ NMR spectra of Ga/MCM-41 composites at room temperature, Fig. 7a, all exhibit a sharp Knight-shifted signal at about $4477 \mathrm{ppm}$, which corresponds to liquid metallic Ga. The strength of this signal shows that the bulk of the $\mathrm{Ga}$ in these $\mathrm{Ga} /$ MCM-41 samples is $\mathrm{Ga}^{0}$. However, a broad weak signal can also be seen in the diamagnetic shift region when the intensity scale is expanded (Fig. 7b), which can be assigned to a small amount of tetrahedral and octahedral $\mathrm{Ga}$ in oxidized states [35]. The presence of conductive metallic gallium is another reason for raising concern about the interpretation of the quantitative NMR measurements, since the radiofrequency waves (r.f.) will only penetrate to a certain depth, usually referred to as the

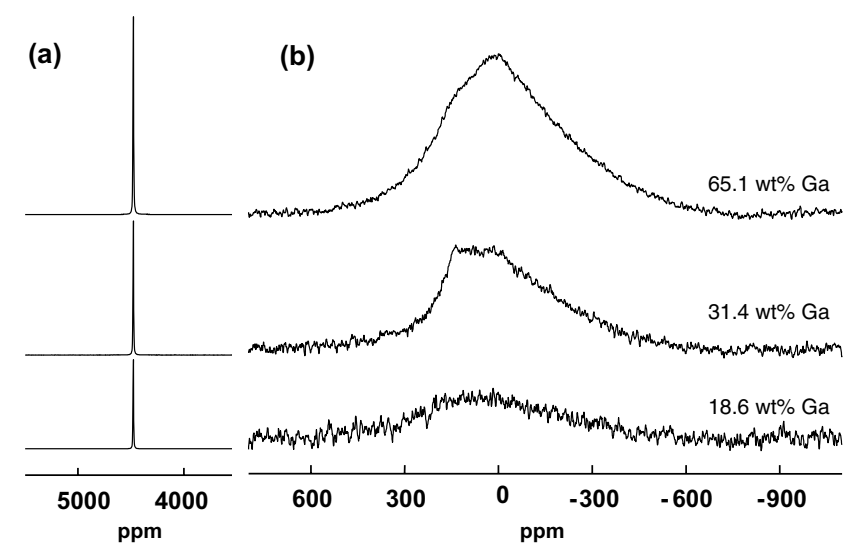

Fig. 7. Static ${ }^{71} \mathrm{Ga}$ NMR spectra at $182.9 \mathrm{MHz}$ of $\mathrm{Ga} / \mathrm{MCM}-41$ composites at room temperature showing (a) the Knight shifted liquid line, and (b) the diamagnetic shift region.
Table 4

Amount of Ga observed by quantitative ${ }^{71} \mathrm{Ga}$ NMR

\begin{tabular}{lll}
\hline $\begin{array}{l}\text { Ga actual } \\
\text { (g/g-sample) }\end{array}$ & $\begin{array}{l}\text { Ga observed by NMR } \\
\text { (g/g-sample) }\end{array}$ & Observed/actual (\%) \\
\hline 0.186 & 0.12 & 64.5 \\
0.314 & 0.19 & 60.5 \\
0.651 & 0.33 & 50.7 \\
\hline
\end{tabular}

"skin-depth". Quantitative ${ }^{71}$ Ga NMR measurements of the liquid $\mathrm{Ga}$ in the composites, Table 4, indicate that the amount of metallic Ga observed by NMR is significantly less than the known amount of Ga present and the fraction observed decreases with increasing Ga loading.

These results provide evidence that a skin depth effect is present in these composites which may affect the other NMR nuclei. We calculate that the skin depth for bulk $\mathrm{Ga}$ at $91.5 \mathrm{MHz}$ will be about $20 \mu \mathrm{m}$ (for the ${ }^{1} \mathrm{H}$ NMR r.f. at $400 \mathrm{MHz}$ in bulk $\mathrm{Ga}$ this number is $9.4 \mu \mathrm{m}$ ), but for a composite the skin depth will likely increase [36].

\subsection{X-ray photoelectron spectroscopy}

The XPS results, Fig. 8, provide information about the oxidation states of $\mathrm{Ga}$ in the surface regions of the sample to a depth of between 1.5 and $6 \mathrm{~nm}$ [37a]. The binding energy of Ga $2 p$ photoelectrons, between 1110 and $1130 \mathrm{eV}$, is characteristic of the different oxidation states of $\mathrm{Ga}$, since there is no overlap with oxygen and silicon photoelectron peaks in this range [37b]. The strongest peak in all the Ga $2 \mathrm{p}_{3 / 2}$ XPS spectra, at $1118.3 \mathrm{eV}$, is attributed to the $\mathrm{Ga}^{\mathrm{I}}$ species [37b]. The weak shoulders on either side of the main peak at

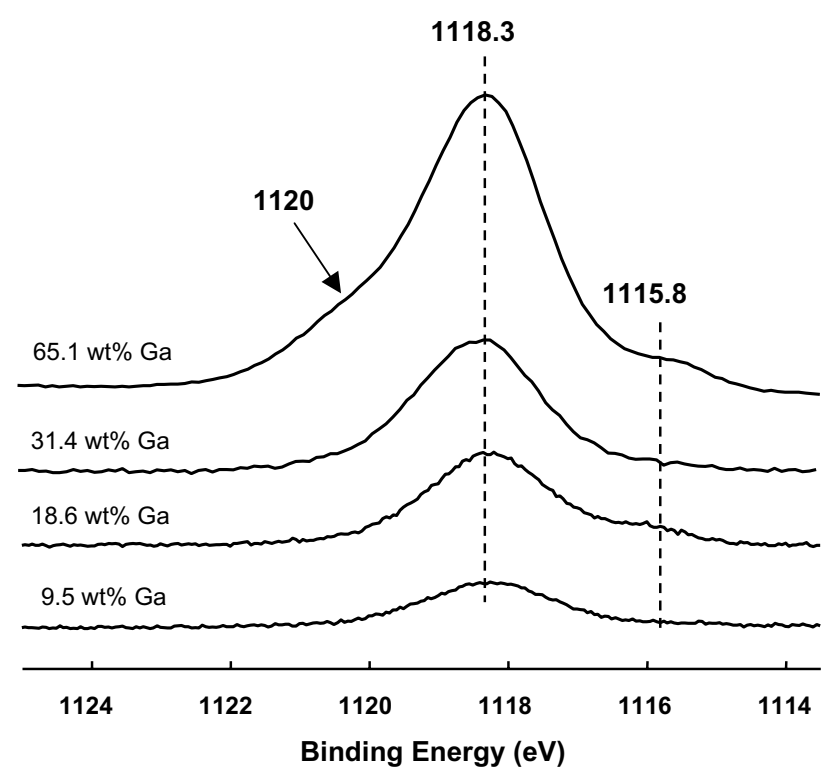

Fig. 8. Ga $2 \mathrm{p}_{3 / 2}$ X-ray photoelectron spectra of Ga/MCM-41 composites. 
1115.8 and $1120 \mathrm{eV}$ are tentatively assigned to non-oxidized $\mathrm{Ga}^{0}$ and $\mathrm{Ga}^{\mathrm{III}}$, respectively [37b]. The $1120 \mathrm{eV}$ line is observed only at the highest loading (i.e. $65.1 \mathrm{wt} \% \mathrm{Ga}$ sample), and is possibly due to $\mathrm{Ga}^{\mathrm{III}}$ produced by surface oxidation of exposed metal by air. Thus, XPS suggests that $\mathrm{Ga}^{\mathrm{I}}$ and not $\mathrm{Ga}^{0}$ or $\mathrm{Ga}^{\mathrm{III}}$ species are predominant in the surface layers of the composites, and these species contribute to the weak diamagnetic signal in the ${ }^{71} \mathrm{Ga}$ NMR. At first sight this observation is surprising, and raises the question as to why XPS sees mainly $\mathrm{Ga}^{\mathrm{I}}$ and not $\mathrm{Ga}^{0}$, which NMR shows is predominant in the bulk material. In this regard it is useful to consider what constitutes the surface layer of the composite material. A picture of the composite as a kind of conglomerate has already emerged in the discussion above, consisting of MCM-41 particles with most of the gallium occupying space between them and perhaps some in the channels. No doubt there will be regions of gallium exposed at the surface, but most likely the bulk of the outside surface will be MCM-41 walls. In this situation the XPS will report on a lot of interface between the framework and Ga both at particle surfaces and inside channels and it is at such interfaces where one might expect to see $\mathrm{Ga}^{\mathrm{I}}$. Most of the bulk $\mathrm{Ga}^{0}$ is apparently buried further away from the surface.

\section{Conclusions}

In the above we have discussed numerous individual pieces of information from diverse experiments and interpreted them collectively to produce a consistent picture of the Ga/MCM-41 composite material. In the highest loaded sample, where $\mathrm{Ga}$ was supplied in an amount more than enough to completely fill the channels, only $\sim 25 \%$ of the pore space was actually lost, and even then it is not certain whether gallium fills this space or simply blocks it. High-angle PXRD, DSC and ${ }^{71}$ Ga NMR showed that under ambient conditions most of the $\mathrm{Ga}$ is present in these samples as liquid bulk metal, as also found in a recent XANES study. This freezing point depression and the complex low temperature solid phase behaviour of the Ga is characteristic of confined $\mathrm{Ga}$, but the porosimetry and low temperature PXRD indicate that the Ga is mostly outside the channels. One must therefore conclude that a large proportion of the $\mathrm{Ga}$ is to be found between the particles of MCM-41. Furthermore, solid-state NMR and XPS results indicate that the Ga at the Ga-MCM-41 interface has reacted with the weakly acidic silanol groups to form new $\mathrm{Ga}^{+}$species like $\mathrm{Si}-\mathrm{O}-\mathrm{Ga}$, or $\mathrm{Si}-\mathrm{O}-\mathrm{Ga}$ bridging to the $\mathrm{O}$ of an adjacent $\mathrm{Si}-\mathrm{O}-\mathrm{H}$. Caution must be exercised when interpreting the NMR of composite materials where one component is metallic, as the r.f. may not penetrate the whole material. Not only does NMR have a problem, but also PXRD because of absorption, and thus two of the most powerful microscopic characterization techniques are rendered less useful than they might be.

\section{Acknowledgments}

We gratefully acknowledge Mr. Gerald Pleizier (ICPET, NRC) for recording the XPS data, and Dr. Gary Enright for useful discussion regarding the PXRD results. This research was made possible by an NRC (Canada) - NSC (Taiwan) Collaborative Research Grant.

\section{References}

[1] A.P. Alivisatos, Science 271 (1996) 933.

[2] J. Hu, T.W. Odom, C.M. Lieber, Acc. Chem. Res. 32 (1999) 435.

[3] (a) J. He, Y. Ba, C.I. Ratcliffe, J.A. Ripmeester, D.D. Klug, J.S. Tse, K.F. Preston, J. Am. Chem. Soc. 120 (1998) 10697;

(b) V.V. Terskikh, I.L. Moudrakovski, C.I. Ratcliffe, J.A. Ripmeester, J. Am. Chem. Soc. 123 (2001) 2891.

[4] (a) E. Shabanova, E.V. Charnaya, K. Schaumburg, Y.A. Kumzerov, J. Magn. Reson. Ser. A 122 (1996) 67;

(b) E.V. Charnaya, C. Tien, K.J. Lin, Y.A. Kumzerov, Phys. Rev. B 58 (1998) 11089;

(c) M.H. Huang, A. Choudrey, P. Yang, Chem. Commun. (2000) 1271 ;

(d) Y.J. Han, J.M. Kim, G.D. Stucky, Chem. Mater. 12 (2000) 2068;

(e) N.R.B. Coleman, N. O’Sullivan, K.M. Ryan, T.A. Crowley, M.A. Morris, T.R. Spalding, D.C. Steytler, J.D. Holmes, J. Am. Chem. Soc. 123 (2001) 7010.

[5] (a) A. Govindaraj, B.C. Satishkumar, M. Nath, C.N.R. Rao, Chem. Mater. 12 (2000) 202;

(b) C. Pham-Huu, N. Keller, C. Estournès, G. Ehret, M.J. Ledoux, Chem. Commun. (2002) 1882.

[6] C.T. Kresge, M.E. Leonowiez, W.J. Roth, J.C. Vartuli, J.S. Beck, Nature 359 (1992) 710.

[7] S. Biz, M.L. Occelli, Catal. Rev.-Sci. Eng. 40 (1998) 329.

[8] B.J. Aronson, C.F. Blanford, A. Stein, Chem. Mater. 9 (1997) 2842.

[9] V.I. Srdanov, I. Alxeit, G.D. Stucky, C.M. Reaves, S.P. DenBaars, J. Phys. Chem. B 102 (1998) 3341.

[10] D.R. Lide (Ed.), CRC Handbook of Chemistry and Physics, 82nd ed., CRC Press, Boca Raton, 2001.

[11] G. Engelhardt, D. Michel (Eds.), High-Resolution Solid-State NMR of Silicates and Zeolite, Wiley, New York, 1987.

[12] M. Hunger, Catal. Rev.-Sci. Eng. 39 (1997) 345.

[13] M. Müller, G. Harvey, R. Prins, Micropor. Mesopor. Mater. 34 (2000) 281.

[14] (a) W. Zhang, M. Sun, R. Prins, J. Phys. Chem. B 106 (2002) 11805 ;

(b) W. Zhang, M. Sun, R. Prins, J. Phys. Chem. B 107 (2003) 10977.

[15] M. Kruk, M. Jaroniec, A. Sayari, Micropor. Mesopor. Mater. 35-36 (2000) 545.

[16] H. Du, V.V. Terskikh, C.I. Ratcliffe, J.A. Ripmeester, J. Am. Chem. Soc. 124 (2002) 4216.

[17] S.J. Gregg, K.S.W. Sing, Adsorption, Surface Area and Porosity, Academic Press, London, 1982.

[18] (a) Z. Luan, H. He, W. Zhou, C. Cheng, J. Klinowski, J. Chem. Soc., Faraday Trans. 91 (1995) 2955; 
(b) G. Schulz-Ekloff, J. Rathousky, A. Zukal, Micropor. Mesopor. Mater. 27 (1999) 273.

[19] E.P. Barrett, L.G. Joyner, P.P. Halenda, J. Am. Chem. Soc. 73 (1951) 373.

[20] B. Marler, U. Oberhagemann, S. Vortmann, H. Gies, Micropor. Mater. 6 (1996) 375.

[21] H. Winkler, A. Birkner, V. Hagen, I. Wolf, R. Schmechel, H. von Seggern, R.A. Fischer, Adv. Mater. 11 (1999) 1444.

[22] M. Kruk, M. Jaroniec, A. Sayari, J. Phys. Chem. B 101 (1997) 583.

[23] M. Jaroniec, M. Kruk, A. Sayari, Stud. Surf. Sci. Catal. 141 (2002) 437.

[24] M.J. MacLachlan, M. Ginzburg, N. Coombs, N.P. Raju, J.E. Greedan, G.A. Ozin, I. Manners, J. Am. Chem. Soc. 122 (2000) 3878.

[25] (a) B.F. Borisov, E.V. Charnaya, W.D. Hoffmann, D. Michel, A.V. Shelyapin, Y.A. Kumzerov, J. Phys. Condens. Matter 9 (1997) 3377 ;

(b) B.F. Borisov, E.V. Charnaya, T. Loeser, D. Michel, C. Tien, C.S. Wur, Y.A. Kumzerov, J. Phys. Condens. Matter 11 (1999) 10259.

[26] A. Di Cicco, S. Fusari, S. Stizza, Philos. Mag. B 79 (1999) 2113.

[27] R. Jenkins, R.L. Snyder, Chem. Anal. 138 (1996) 90.
[28] B.H. Wouters, T. Chen, M. Dewilde, P.J. Grobet, Micropor. Mesopor. Mater. 44-45 (2001) 453.

[29] M. Xu, A. Arnold, A. Buchholz, W. Wang, M. Hunger, J. Phys. Chem. B 106 (2002) 12140.

[30] R. Fricke, H. Kosslick, G. Lischke, M. Richter, Chem. Rev. 100 (2000) 2303

[31] R. Challoner, R.K. Harris, S.A.I. Barri, M.J. Taylor, Zeolites 11 (1991) 827.

[32] X.S. Zhao, G.Q. Lu, J. Phys. Chem. B 102 (1998) 1556.

[33] H. He, C.F. Cheng, S. Seal, T.L. Barr, J. Klinowski, J. Phys. Chem. 99 (1995) 3235.

[34] G.E. Maciel, C.E. Bronnimann, R.C. Zeigler, I.S. Chuang, D.R. Kinney, E.A. Keiter, in: H.E. Bergna (Ed.), The Colloid Chemistry of S'ilica, Advances in Chemistry Series, vol. 234, American Chemical Society, Washington, DC, 1994, p. 269.

[35] H.K.C. Timken, E. Oldfield, J. Am. Chem. Soc. 109 (1987) 7669.

[36] N.W. Ashcroft, N.D. Mermin, Solid State Physics, Saunders College Publishing/Harcourt Brace College Publishers, New York, 1976, p. 277.

[37] (a) M. Stöcker, Micropor. Mater. 6 (1996) 235;

(b) C.D. Wagner, W.M. Riggs, L.E. Davis, J.F. Moulder, G.E. Muilenberg (Eds.), Handbook of X-ray Photoelectron Spectroscopy, Perkin-Elmer, Eden Prairie, MN, 1992. 